\title{
Local Expression of Antiinflammatory Cytokines in Cancer
}

Masahiro Yamamura, * Robert L. Modlin, ** Jeffrey D. Ohmen, * and Ronald L. Moy * \$॥

${ }^{*}$ Division of Dermatology and ${ }^{\ddagger}$ Department of Microbiology and Immunology, University of California at Los Angeles School of Medicine, Los Angeles, California 90024; ${ }^{\S}$ Veterans Administration West Los Angeles Medical Center, Los Angeles, California 90024; and "University of California at Los Angeles, Jonsson Comprehensive Cancer Center, Los Angeles, California 90024

\section{Abstract}

To characterize the nature of the local cytokine response to cancer, we chose to investigate cytokine patterns in biopsy specimens of basal cell carcinoma (BCC). We hypothesized that a distinct pattern of local cytokine production may be characteristic of BCC, a neoplasia of epidermis, in comparison to the pattern of seborrheic keratosis (SK), a benign growth of epidermis. We analyzed cytokine mRNAs in BCC versus SK by performing polymerase chain reaction on $m R N A$ derived from biopsy specimens. The mRNAs encoding cytokines for IL-4, IL-5, IL-10, and granulocyte macrophage colony-stimulating factor were strongly expressed in BCC lesions and weakly expressed in SK lesions. Conversely, IL-2, IFN- $\gamma$, and lymphotoxin mRNAs were strongly expressed in SK lesions and weakly expressed in $\mathrm{BCC}$ lesions. The response to malignancy, BCC, was typified by cytokines characteristic of murine $T_{H} 2$ cells. This cytokine pattern favors humoral immunity with concomitant immunosuppression of cell-mediated immune responses. In comparison, the response to the benign growth, SK, was typified by cytokines characteristic of murine $T_{H} 1$ cells that favor cell-mediated immune reactions. The findings of a distinct cytokine pattern in skin cancer provide a framework to develop strategies for immunologic intervention. (J. Clin. Invest. 1993. 91:1005-1010.) Key words: basal cell carcinoma • cytokines • T lymphocytes • interleukin- 4 • interleukin-10

\section{Introduction}

It is generally believed that the immune response against malignantly transformed cells requires the elaboration of cytokines produced by $\mathrm{T}$ cells. For example, cytokines appear to be essential for the activation of natural killer cells and cytotoxic $T$ lymphocytes to lyse tumor targets. This mechanism has been recently exploited in the design of a variety of cytokine therapies for tumors. These include the $(a)$ direct administration of lymphokines to patients (either systemically or locally), $(b)$ in vitro culture of immune cells from patients with cytokines followed by administration of these so-called lymphokine-activated killer cells to patients (1), (c) the transfection of cytokine genes into $\mathrm{T}$ cells to activate the local antitumor defense (2), and $(d)$ the transfection of cytokine genes into tumors as vaccines to engender and activate cytotoxic $T$ lymphocytes in vivo $(3,4)$. Such therapeutic protocols assume that the cell-me-

Address correspondence to Ronald L. Moy, M.D., Division of Dermatology, 200 UCLA Medical Plaza, Suite 465, Los Angeles, CA 900246975.

Received for publication 18 February 1992 and in revised form 17 August 1992.

The Journal of Clinical Investigation, Inc.

Volume 91, March 1993, 1005-1010 diated immune response to cancer is suboptimal and augmentation of the response will result in a successful antitumor response.

To more fully characterize the host response against neoplasms, we chose to investigate the pattern of local cytokine production in basal cell carcinoma (BCC). ${ }^{1}$ BCC provides an extraordinary opportunity to study the nature of the local cytokine response. As cancers of the skin, the lesions are readily accessible for biopsy and study. More importantly, the immune response appears to play an important role in the course of this cancer. Although these neoplasms rarely metastasize, they frequently are invasive. In immunosuppressed individuals, BCCs are more numerous (5). The prominence of the host inflammatory response around resolving tumors suggests a role for the immune response in eliminating the tumor (6). Finally, intralesional administration of cytokines, such as IL-2, IFN- $\gamma$, and IFN- $\alpha$, can induce resolution of these tumors (7-10).

Studies have addressed the production in vitro of cytokines by tumor-infiltrating lymphocytes derived from other cancers, although without comparison to lymphocytes from benign lesions (11). We wanted to examine the local cytokine production in situ unbiased by manipulation of these cells in tissue culture. We hypothesized that a distinct pattern of local cytokine production may be characteristic of $\mathrm{BCC}$, in comparison to that of a benign growth. Since BCC represents a malignant growth of epidermis, we compared the cytokine pattern in BCC to irritated seborrheic keratosis (SK), which represents a benign hyperplasia of the epidermis. This was accomplished by performing PCR on mRNA derived from these specimens.

\section{Methods}

Specimens. 10 BCC tissue specimens were obtained from excisional biopsies after informed consent. These were clinically and histologically typical BCC, not recurrent or aggressive, and consisted predominantly of central tumor without dermis. Seven irritated SKs were chosen for comparison as benign lesions. These SKs were clinically inflamed and characterized histologically by a dense lymphocytic infiltrate. Biopsy specimens were placed in OCT medium (Ames Co., Elkhart, IN), snap frozen in liquid nitrogen, and stored at $-70^{\circ} \mathrm{C}$.

RNA isolation and CDNA synthesis. 40-50 5- $\mu \mathrm{m}$ sections of each biopsy specimen were lysed in $0.5 \mathrm{ml}$ guanidinium buffer ( $4 \mathrm{M}$ guanidinium isothiocyanate, $50 \mathrm{mM}$ Tris- $\mathrm{HCl}, 10 \mathrm{mM}$ EDTA, 2\% sarcosyl, $100 \mathrm{mM}$ 2-mercaptoethanol). After phenol/chloroform extraction, the lysate was layered onto $5.7 \mathrm{M} \mathrm{CsCl}$ gradient and ultracentrifuged at $50,000 \mathrm{rpm}$ at $20^{\circ} \mathrm{C}$ for $3 \mathrm{~h}$ in a TL- 100 using a TLS-55 rotor (Beckman Instruments, Inc., Fullerton, CA). The RNA pellet was redissolved in the presence of $20 \mathrm{U}$ RNase inhibitor (Boehringer Mannheim Biochemicals, Indianapolis, IN) and treated with $10 \mathrm{U}$ RNase-free DNase I (Promega Biotec, Madison, WI) for $30 \mathrm{~min}$ at $37^{\circ} \mathrm{C}$ to elimi-

1. Abbreviations used in this paper: BCC, basal cell carcinoma; SK, seborrheic keratosis. 
nate any remaining genomic DNA. Total RNA was precipitated with sodium acetate and ethanol. cDNA was synthesized from mRNA by 1 $h$ incubation at $42^{\circ} \mathrm{C}$ with avian myeloblastosis virus reverse transcriptase (Bethesda Research Laboratories, Gaithersburg, MD) and polydT (Pharmacia Inc., Piscataway, NJ) priming.

PCR analysis. PCR was performed as previously described (12). Briefly, the PCR reaction mixture contained $10 \mathrm{mM}$ Tris- $\mathrm{HCl}, \mathrm{pH} 9.0$; $50 \mathrm{mM} \mathrm{KCl} ; 0.01 \%$ (wt/ vol) gelatin; $2.5 \mathrm{mM} \mathrm{MgCl}$; $0.2 \mathrm{mM} \mathrm{dNTP}$; $1.0 \mu \mathrm{M} \mathrm{5} 5^{\prime}$ and 3 ' oligonucleotide primers; and $2.5 \mathrm{U}$ Taq polymerase (Promega Biotec). The oligonucleotides primer sequences have been previously reported (13). These included primers for $\beta$-actin, CD3 $\sigma$, IL-1 $\beta$, IL-2, IL-4, IL-5, IL-6, IL-10, GM-CSF, TNF- $\alpha$, IFN- $\gamma$, and lymphotoxin. Samples were then amplified in a DNA thermocycler (Perkin-Elmer Corp., Norwalk, CT) for 35 or 40 cycles. Each cycle consisted of denaturation at $94^{\circ} \mathrm{C}$ for $1 \mathrm{~min}$ and annealing/extension at $55^{\circ} \mathrm{C}$ (for IL- 2 and IFN- $\gamma$ ) or $65^{\circ} \mathrm{C}$ for $2 \mathrm{~min}$ (all other cytokines). An aliquot of PCR product was then electrophoresed on $2 \%$ agarose gels and visualized by ethidium bromide staining.

Radioactive hybridization and quantification of PCR product. To verify that PCR amplification was specific for cytokine mRNA, PCR products were transferred to Hybond-N nylon membranes (Amersham Corp., Arlington Heights, IL) and probed with a radiolabeled oligonucleotide complementary to sequences within the region flanked by a pair of cytokine primers. The sequences of cytokine internal probes have also been reported (13). Blots were hybridized at $55^{\circ} \mathrm{C}$ with $\gamma-{ }^{32} \mathrm{P}\left({ }^{32} \mathrm{P}-\gamma \mathrm{ATP} ; 7,000 \mathrm{Ci} / \mathrm{mM}\right.$; ICN Pharmaceuticals, Inc., Costa Mesa, CA) labeled probe on the $5^{\prime}$ end by $\mathrm{T} 4$ polynucleotide kinase (Boehringer Mannheim Biochemicals) for $4 \mathrm{~h}$. Membranes were then washed for $10 \mathrm{~min}$ with $2 \times$ SSC and $0.1 \%$ SDS, followed by $0.2 \times$ SSC and $0.1 \%$ SDS at ambient temperature, and subjected to autoradiography.

PCR products were quantified using a radioanalytic imaging system (AMBIS; Automated Microbiology Systems, Inc., San Diego, CA). Probed membranes were scanned for 1 to $3 \mathrm{~h}$ and the amount of radioactivity bound to $P C R$ products present in any one lane was determined. The relative intensity of individual bands was expressed as relative cpm. The most intense band was assigned the value of 100 and the intensity of other bands expressed proportionately. Statistical differences between patient groups were assessed by Students' $t$ test. The Wilcoxon Rank-Sum test was used for the lymphotoxin data because the data were not normally distributed.

Verification of PCR. PCR analysis of 10 -fold serially diluted plasmids containing IL-2, IL-4, IL-6, IL-10, IFN- $\gamma$, and TNF- $\alpha$ cDNAs with visualization by ethidium bromide staining indicated that our PCR procedure was sensitive to $10^{2}-10^{3}$ copies of template for each cytokine. Furthermore, the intensity of the PCR product increased accordingly from the number of copies of starting plasmid to $\geq 10^{7}$ $10^{9}$ copies (12).

To demonstrate that our comparative PCR strategy is valid throughout a range of cDNA concentrations, 10-fold serial dilutions of IL-2, IL-4, IL-6, IL-10, IFN- $\gamma$, and TNF- $\alpha$ cDNA containing plasmids were subjected to PCR, probe hybridization, and quantification by radioanalytic scanning (13). As indicated in Fig. 1, there was a log-linear correlation between the number of starting copies of plasmid and the yield of PCR products across the range of plasmid concentrations investigated. Adding IFN- $\gamma$ cDNA to serial dilutions of IL- 10 cDNA did not alter the amount of IL-10 PCR product (data not shown). Our tissue cDNA samples were in the linear part of the plasmid titration, according to the intensity of PCR products. These results indicate that our PCR conditions provide meaningful comparison of the small amounts of cytokine mRNAs present in lesions.

A number of controls were employed to ensure accurate comparisons of the different samples studied. Upon PCR amplification of serial 10-fold dilutions of sample cDNAs, a concomitant decrease in the PCR product was observed. Similarly, varying the number of PCR cycles did not change the relative differences between samples. These studies indicate that our PCR conditions are not within the plateau phase of amplification. Mixing of cDNAs from different patients did not inhibit or

\section{TITRATION OF IL-10 PLASMID}

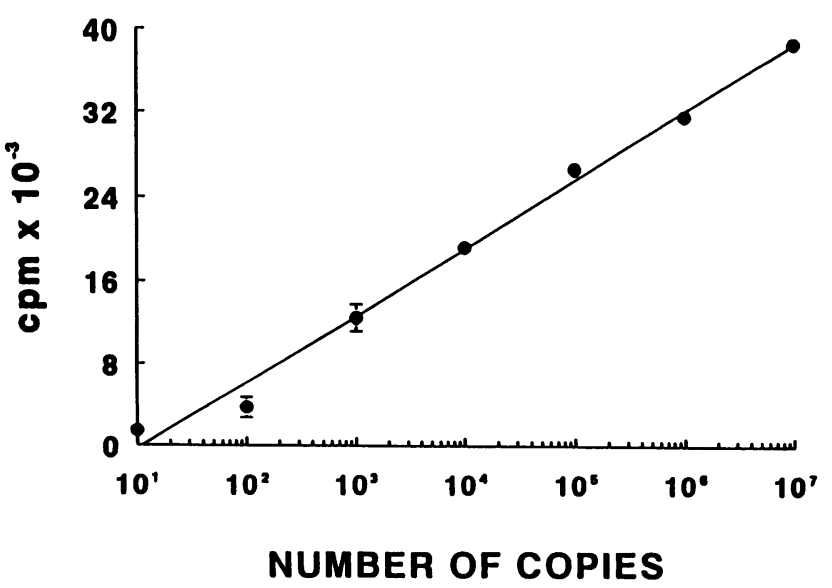

Figure 1. Quantitation of PCR amplification of IL-10 plasmid cDNA. PCR was performed in triplicate for each concentration of plasmid cDNA. The products were electrophoresed, transferred to nylon membranes, and hybridized with a radiolabeled internal oligonucleotide probe. The transfers were then scanned according to radioactivity.

augment PCR amplification, indicating that cDNAs do not directly alter PCR efficiency. Each experiment included a positive control (phorbol myristate acetate and ionomycin-stimulated peripheral blood mononuclear cells) and a negative control (either sample RNA that had not been reverse transcribed or buffer alone). The latter control did not yield PCR product, confirming the absence of extraneous cDNA or PCR product contaminating the samples. In addition, we routinely used extensive precautions to avoid PCR artifact, including assembling reactions in laminar flow hoods, use of aliquoted reagents, pipettes dedicated for assembling PCR reactions, and aerosol resistant tips (Continental Lab Products, La Jolla, CA).

\section{Results}

Because several cytokine mRNAs exist at very low levels in BCC lesions, we extracted total RNA from biopsy specimens and reverse transcribed the polyadenylated mRNAs to synthesize cDNAs. We performed PCR using cytokine-specific primers to compare the cytokine expression within BCC lesions with SK lesions. The cDNAs were normalized to yield equivalent amounts of $\beta$-actin PCR product to standardize the amount of total cellular mRNA in each PCR reaction. This procedure was used to normalize sample cDNAs for analysis of cytokines known to be produced by a variety of cell types. Samples were normalized to yield equivalent amounts of CD3 $\delta$ chain PCR product, as a measure of $\mathrm{T}$ cell mRNA, for cytokines mainly produced by $\mathrm{T}$ lymphocytes.

PCR analysis of cytokines produced by a variety of cell types. Cytokine PCR profiles of BCC lesions were found to be distinctly different from SK lesions. Cytokine mRNAs produced by a variety of cell types, IL-1 $\beta$, IL-6, IL-8, and GMCSF, were generally more abundant in BCC than in SK when visualized by ethidium bromide staining (Fig. $2 A$ ). For IL-1 $\beta$, strong ethidium bromide-stained bands corresponding to the predicted molecular weight were detected in $3 / 5 \mathrm{BCC}$ and only $1 / 3 \mathrm{SK}$. Weaker bands were seen in the other samples. For IL-6, weak bands were seen in 4/5 BCC and none of the SK. For IL-8, PCR product as visualized by ethidium bromide 


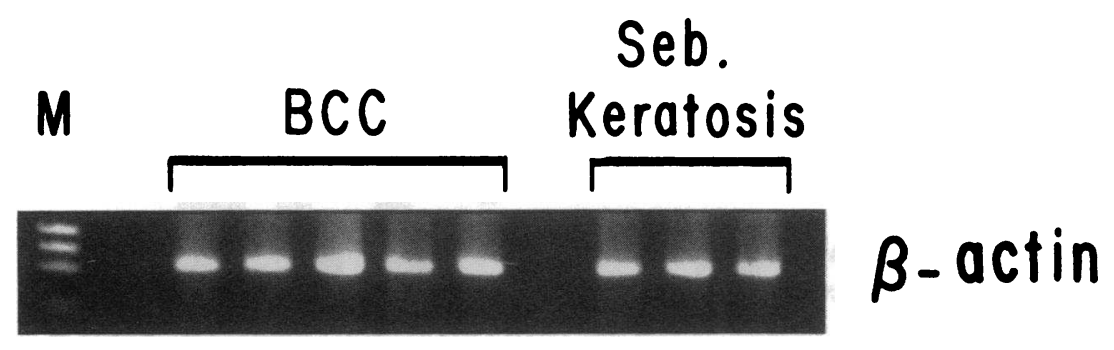

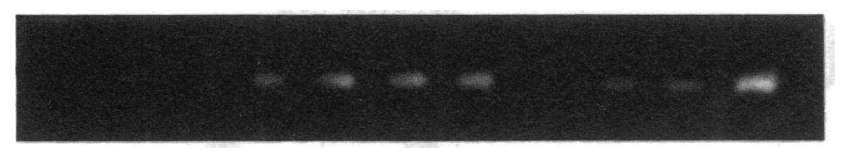
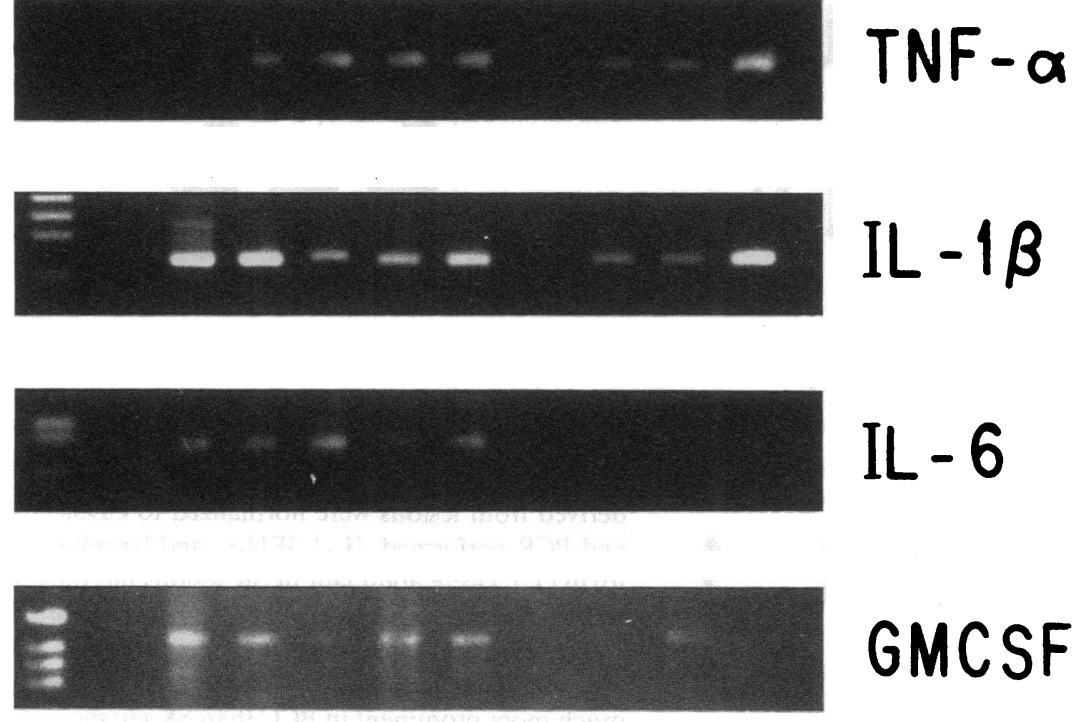

\section{GMCSF}

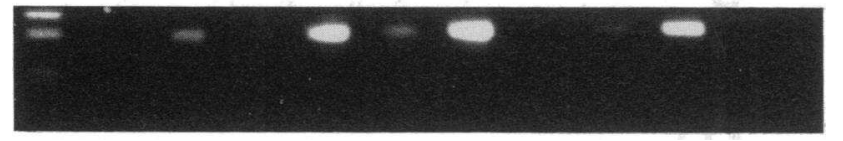

IL -8

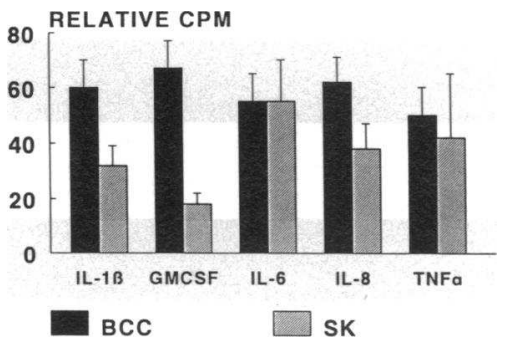

Figure 2. $(A)$ Cytokine mRNAs produced by a variety of cell types. TNF $\alpha$, IL-1 $\beta$, IL-6, IL-8, and GM-CSF were more abundant in BCC lesions than in SK lesions studied when visualized by ethidium bromide staining. ( $B$ ) Quantification of cytokine $m R N A s$ in $B C C$ and SK lesions (mean \pm SEM). The cDNAs derived from lesions were normalized to the $\beta$-actin PCR product. Electrophoresed PCR products for IL$1 \beta$, IL-6, IL-8, GM-CSF, and TNF- $\alpha$ were probed with a radiolabeled oligonucleotide derived from a sequence internal to the primer sequences. $B C C$, basal cell carcinoma; $S K$, seborrheic keratosis. staining was seen in $2 / 5 \mathrm{BCC}$ and weak bands in $2 / 5$ other BCC; whereas, in contrast, product was seen in only $1 / 3 \mathrm{SK}$. For GM-CSF, strong ethidium bromide bands could be visualized for 4/ 5 BCC and a weak band in $1 / 3$ SK. TNF- $\alpha$ mRNA was almost equivalent in BCC versus SK, with PCR product being prominent in $4 / 5 \mathrm{BCC}$ specimens and $3 / 3$ SK specimens.

Quantification of these PCR products was accomplished by probing, using radiolabeled oligonucleotides specific for cytokine sequences followed by radioanalytic imaging. This analysis indicated that the mean GM-CSF PCR product was more than threefold higher in BCC than in SK whereas the mean IL- $1 \beta$ was twofold higher in BCC. IL- 6 and IL- 8 PCR products were less than twofold elevated in BCC compared with SK. TNF- $\alpha$ PCR product was similarly expressed in BCC compared with SK (Fig. $2 B$ ).

$P C R$ analysis of cytokines produced mainly by $T$ cells. In evaluating the production of cytokine $m R$ NAs produced by $T$ cells, two distinct patterns emerged. IL- 2 and IFN- $\gamma$ mRNAs, "Type 1" (14) or $T_{H} 1$ cytokines characteristic of $T$ cells involved in cell-mediated immune responses, were more abundant in SK lesions than in BCC lesions. Fig. $3 \mathrm{~A}$ shows representative PCR products from eight samples. IL-2 PCR product could be visualized by ethidium bromide staining in $2 / 3 \mathrm{SK}$ but $0 / 5$ BCC. Similarly, IFN- $\gamma$ PCR product was detected in $3 / 3$ SK. IFN- $\gamma$ PCR product was strongly evident in $1 / 5$ BCC, although weakly expressed in two additional BCC. Lymphotoxin mRNAs, also characteristic of Type $1 \mathrm{~T}$ cells, were strongly expressed in $2 / 3$ SK specimens but only $2 / 5$ BCC specimens.

Comparative analysis of the PCR products of $10 \mathrm{BCC}$ lesions and 7 SK lesions after hybridization with radiolabeled specific internal probes demonstrated that the mean relative cpm for IL-2 and IFN- $\gamma$ PCR products were two- to fourfold higher in SK specimens than BCC specimens (Fig. $3 B$ ). These differences were statistically significant as follows: for IL-2, $P$ $=0.02$; for IFN- $\gamma, P<0.05$; and for lymphotoxin, $P<0.01$. The titration of plasmid cDNAs indicates that two- to fourfold differences in relative cpm represent $\geq 100-1,000$-fold differences in sample cDNA.

In contrast, IL-4, IL-5, and IL-10 mRNAs, typical of "Type 2" (14) or $\mathrm{T}_{\mathrm{H}} 2 \mathrm{~T}$ cells, which favor humoral immunity but can also result in immunosuppression of cell-mediated responses $(12,14)$, appeared more prominent in BCC lesions than SK lesions. Fig. $3 A$ shows representative patterns from eight samples. IL-4 and IL-5 PCR products were prominent in 3/5 BCC but not visible in the $3 \mathrm{SK}$. IL-10 PCR product was prominent in $2 / 5 \mathrm{BCC}$ specimens, with moderate PCR product in $3 / 5$ 

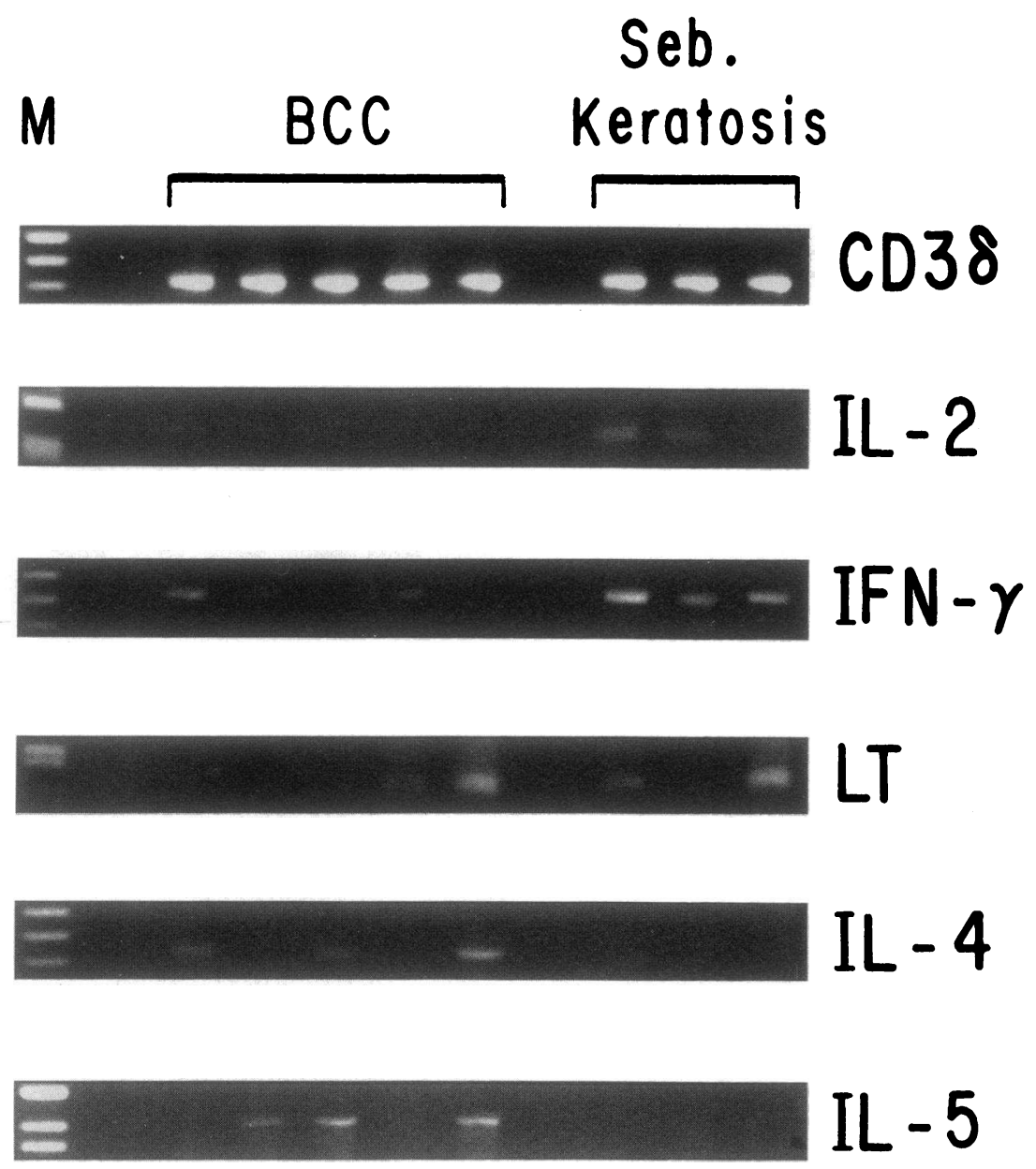

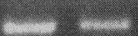

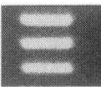

IF $-\gamma$
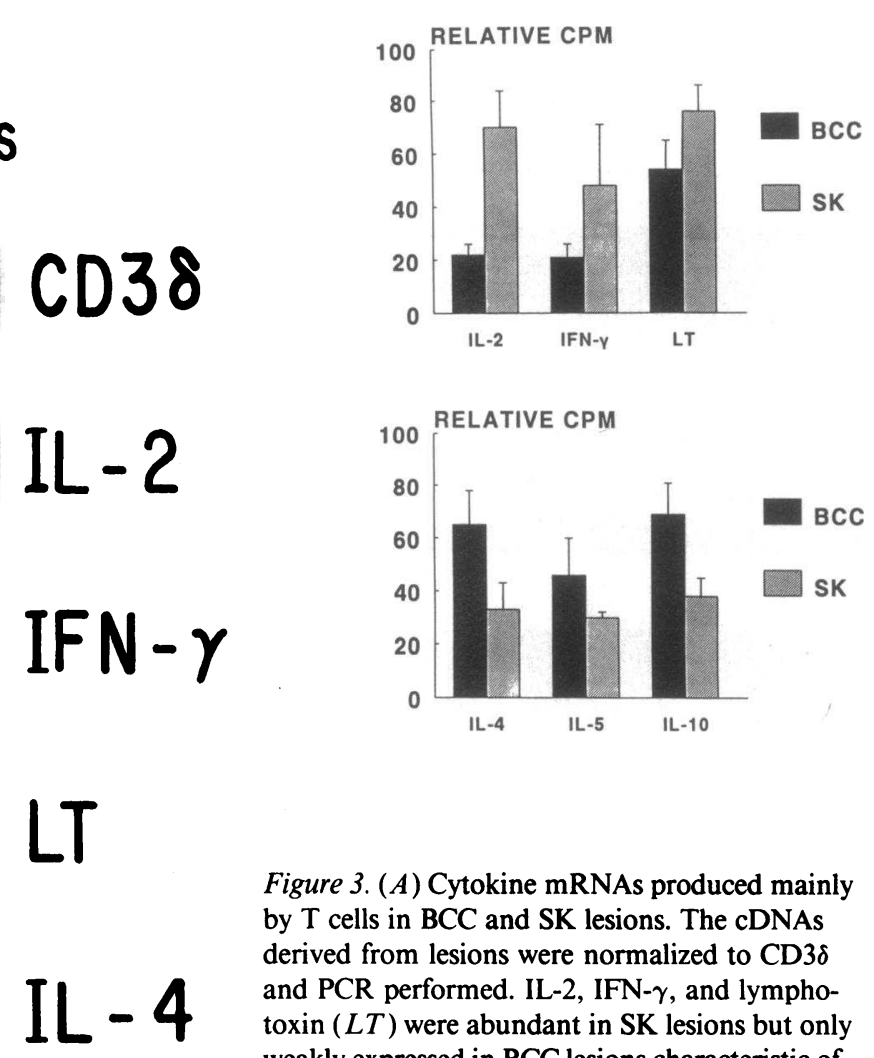

Figure 3. $(A)$ Cytokine mRNAs produced mainly by $\mathrm{T}$ cells in BCC and SK lesions. The cDNAs derived from lesions were normalized to $\mathrm{CD} 3 \delta$ and PCR performed. IL-2, IFN- $\gamma$, and lymphotoxin $(L T)$ were abundant in SK lesions but only weakly expressed in BCC lesions characteristic of Type 1 cytokines of cell-mediated immunity. In contrast, IL-4, IL-5, and IL-10 mRNAs appeared much more prominent in BCC than SK characteristic of Type 2 cytokines of humoral immunity and suppression of cell-mediated immunity when visualized by ethidium bromide staining. $(B)$ Quantification of Type 1 cytokine mRNAs in 10 $\mathrm{BCC}$ and $5 \mathrm{SK}$ lesions (mean \pm SEM). ( $C$ ) Quantification of Type 2 cytokine mRNAs in 10 BCC and $5 \mathrm{SK}$ lesions (mean \pm SEM).
BCC specimens. In contrast, prominent IL-10 product could not be detected in SK lesions, but only moderate PCR product could be visualized from 1/3 SK specimens.

Quantification of PCR product for these cytokines in 10 BCC and 7 SK specimens is presented in Fig. $3 C$. The mean relative cpm for IL-4 and IL-10 PCR product was about two-

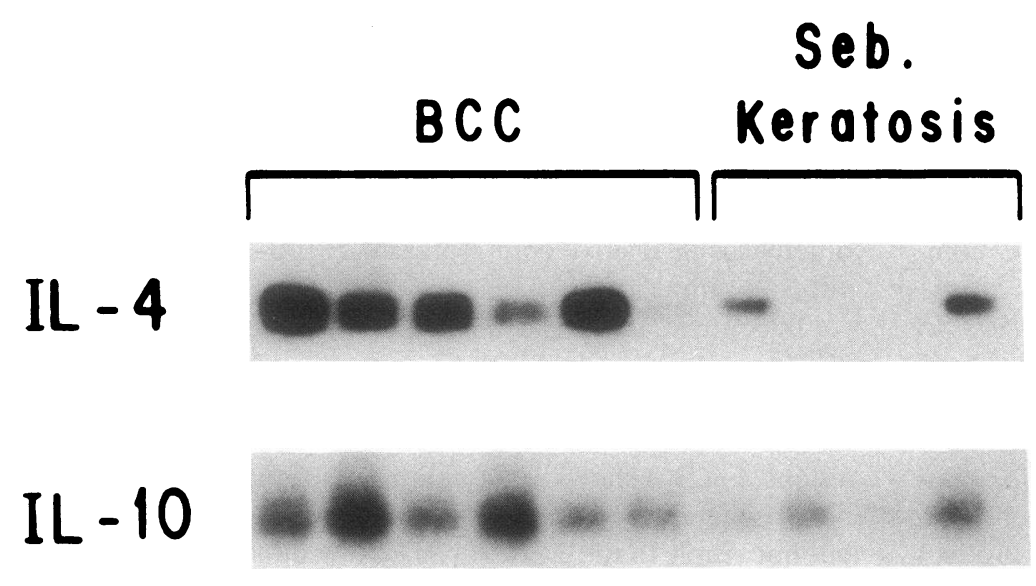

Seb.

fold higher in BCC lesions than SK lesions. The abundance of IL-4 in BCC relative to SK was statistically significant for IL-4 $(P=0.02)$ and for IL-10 $(P<0.05)$. Representative southern transfers of IL-4 and IL-10 PCR products are shown in Fig. 4. The IL-4 PCR product was more strikingly evident in BCC lesions than SK lesions. IL-10 PCR product was also increased,
Figure 4. Comparison of mRNA in BCC and SK lesions. Electrophoresed PCR products for IL-4 and IL-10 were probed with a radiolabeled oligonucleotide derived from a sequence internal to the primers used for PCR. 
but to a lesser extent, in BCC compared with SK. Titration of plasmid containing IL-4 and IL-10 cDNA indicated that the twofold differences in relative cpm represent $\sim 100-1,000$ fold differences in sample cDNA. The IL-5 PCR product from BCC lesions appeared to be greater than that from SK lesions, but this difference did not achieve statistical significance.

\section{Discussion}

Of particular importance in understanding the immune response to cancer is the specific pattern of cytokines produced locally, since immunotherapy is often directed towards altering these patterns. To investigate the cytokine response in small tumor biopsy specimens, we have adapted the PCR technique to determine the pattern of expression of 11 cytokines. This was accomplished by comparing the immune response in a malignant tumor of the epidermis, BCC, to that of a benign growth of the epidermis, SK. In comparing the cytokines produced by $T$ cells, we noted two strikingly distinct patterns. IL-4 and IL-10 were the dominant cytokine mRNAs noted in BCC specimens whereas, in contrast, IL- 2 and IFN- $\gamma$ were identified as the predominant cytokines in SK.

The present data provides a framework in which to understand the cytokine network involved in the local immune response to tumors. As such, it is intriguing to compare these findings with the cytokine patterns of immunoregulatory subsets of murine CD4+ cells (15). In the mouse, CD4+ T cells producing IFN- $\gamma$ and IL- 2 are termed $T_{H} 1$ cells and participate in cell-mediated immune responses. In contrast, $\mathrm{CD} 4+\mathrm{T}$ cells producing IL-4, IL-5, and IL-10 compose $\mathrm{T}_{\mathrm{H}} 2$ cells and are involved in humoral responses. These functional subsets appear to regulate the immune response to infection in murine models; $T_{H} 1$ cytokines are associated with resistance to infection and $T_{H} 2$ cytokines are associated with susceptibility to infection (16-18). There is a cross-regulatory circuit in that IFN- $\gamma$ inhibits proliferation of $T_{H} 2$ cells and IL- 4 together with IL-10 downregulate $T_{H} 1$ responses. Similar subpopulations of human $\mathrm{T}$ cells that secrete distinct cytokine patterns have been identified (19-21) and have been similarly termed Type 1 and Type 2. Type 1-like cytokine patterns appear to correlate with host resistance in leprosy; Type 2-like cytokine patterns are associated with susceptibility $(12,14)$. Type 2 -like $T$ cell responses have also been associated with allergy (22) and parasitic infection (23).

Our data suggests that the immune response to benign and malignant growths is also regulated by distinct patterns of cytokines produced locally. The local cytokine response to BCC appears to be Type 2 like, but the response towards a benign growth is Type 1 like. Of particular interest were IL-4 and IL10 , which are prominent in BCC. The fact that mast cells are prominent around BCC is indirect evidence that IL-4 and IL10 are produced locally, since these cytokines stimulate mast cell growth (24). The most likely explanation for an increase in both IL-4 and IL-10 in BCC lesions would be that a single cell type is responsible for their production. To our knowledge the only cell capable of producing both IL- 4 and IL-10 in man is a $\mathrm{T}$ cell. Murine mast cells are capable of producing both cytokines (25), although this has not been shown for human mast cells. It is possible that multiple cell types contribute to this Type 2 cytokine response. IL- 4 can be produced in man by transformed B cells and mast cells (26). IL-10 can also be pro- duced by human B cells and macrophages, as well as by murine keratinocytes (27).

It is intriguing to speculate that the Type 2 cytokine response induces immunosuppression at the tumor site and in this way contributes to the pathogenesis of BCC. For example, IL-4 has been shown to inhibit IL-2 activation of T cells by affecting IL-2 production and IL-2 receptor expression (28) and to oppose the effect of IFN- $\gamma$ (29). Additionally, IL-4 inhibits the production of TNF- $\alpha$ and IL- $1 \beta$ by macrophages and has an antagonistic effect on IL-2-induced lymphocyte cytotoxicity (30). The production of IL-4 by antigen-specific CD8+ T suppressor cells may be mechanistically crucial in their ability to downregulate immune responses (14). IL-10 has been shown to downregulate cytokine production by CD4 T cells $(25,31)$. It is intriguing that tumor-specific suppressor $\mathrm{T}$ cells have been associated with tumor progression in murine models (32). Bloom et al (21) suggests that these murine T cells suppress antitumor immunity via the release of Type 2 cytokines. Similar suppression of the immune response in BCC may facilitate neoplastic growth.

Alternatively, the observed local cytokine patterns may function to limit the spread and growth of these lesions. BCC is a low grade malignancy, in that the tumor rarely metastases, although it can be locally destructive. Study of experiment models suggests a role for Type 2 cytokines in limiting tumor growth. Transfection of the IL-4 gene into tumors results in the generation of a $T$ cell response that resolves tumor foci, recruitment of antigen-presenting cells, and enhancement of tumor antigen presentation (3). The prominence of IL-4 in the lesions of BCC found in this study could be essential for increasing cytolytic function $(33,34)$. However, on balance, the resolution of BCC by intralesional treatment with Type 1 cytokines, including IL-2, suggests that the predominance of Type 2 cytokines is a suboptimal response not sufficient to eliminate the tumor. In addition, other cytokines are likely to be involved in the immune response to cancer. For example, GM-CSF, prominent in $\mathrm{BCC}$, may promote antigen presentation, cause maturation of Langerhans cells, and induce the growth of specific $T$ cell populations (35). It is at this time unclear what the net effect of multiple cytokines are on the outcome of the host response to cancer.

Factors that influence the selective activation of Type 1 or Type 2 responses to benign and malignant tumors are fundamental to our understanding of the immune response to cancer. The nature of the antigen, antigen-presenting cells, MHC haplotype, accessory molecules, and second signals have been considered $(36,37)$. Of interest in this example are Langerhans cells of the epidermis, which can present antigen to both $T_{H} 1$ and $T_{H} 2$ cells ( 38 ). However, ultraviolet (UV)-irradiated Langerhans cells preferentially activate CD4+ cells of the $T_{H} 2$ subset, but not $T_{H} 1$ cells (38). It is tempting to speculate that one of the mechanisms by which UV light contributes to the pathogenesis of skin cancer is by altering antigen-presenting cells to selectively activate Type 2 cytokine-producing cells in the local immune response. Further studies will be required to examine the spectrum of cutaneous tumors, malignant, premalignant, and benign, to more fully define the role of these and other cytokines. Finally, analysis of the clinical response as well as the local cytokine changes induced by the intralesional administration of cytokines will help elucidate mechanisms of the immune response to cancer. The present 
approach provides a framework for choosing and monitoring immunologic intervention in cancer.

\section{Acknowledgments}

We are grateful to Peter Barnes, M.D. for help in the statistical analysis and Catharine Becker for help in the preparation of this manuscript. We thank Teresa McHugh for technical help in sample preparation. We are grateful to Kevin Moore of DNAX Research Institute for providing IL-10 primers and probes and for helpful scientific advice.

Supported by grants from the National Institutes of Health (AI 22553, AR 40312, AI 28508, and CA56860), The Dermatology Research Foundation of California, Inc., University of California Cancer Coordinating Committee, the Sasakawa Memorial Health Foundation, and the Hartford-Gleitzmann Foundation.

\section{References}

1. Rosenberg, S. A., B. S. Packard, P. M. Aeborsold, D. Solomon, S. L. Topalian, S. T. Toy, P. Simon, M. D. Lotze, J. C. Yang, C. A. Seip, et al. 1988. The use of tumor infiltrating and interleukin- 2 in the immunotherapy of patients with metastatic melanoma: a preliminary report. $N$. Engl. J. Med. 319:1676-1680.

2. Fearon, E. R., D. M. Pardoll, and T. Itaya. 1990. Interleukin-2 production by tumor cells abrogates tumorigenicity and induces protective immunity. Cell. 60:397-403.

3. Golumbek, P. T., A. J. Lazemby, H. J. Levitsky, L. M. Jaffee, H. Karusuyama, M. Baker, and D. M. Pardoll. 1991. Treatment of established renal cancer by tumor cells engineered to secrete interleukin-4. Science (Wash. DC). 254:713-716.

4. Gansbacher, B., K. Zier, G. Daniels, K. Cronin, R. Bannerji, and E. Gilboa 1990. Murine interleukin-4 displays potent antitumor activity in vivo. J. Exp. Med. 172:1217-1224.

5. Sitz, K. V., M. Keppen, and D. F. Johnson. 1987. Metastatic basal cell carcinoma in acquired immunodeficiency syndrome-related complex. $J A M A(J$. Am. Med. Assoc.). 257:340-343.

6. Curson, C., and D. Weedon. 1979. Spontaneous regression in basal cell carcinomas. J. Cutaneous Pathol. 6:432-437.

7. Cornell, R. C., H. T. Greenway, S. B. Tucker, L. Edwards, S. Ashworth J. C. Vance, D. J. Tanner, E. L. Taylor, K. A. Smiles, and E. A. Peets. 1990 Intralesional interferon therapy for basal cell carcinoma. J. Am. Acad. Dermatol. 23:694-700.

8. Mozzanica, N., A. Cattaneo, V. Boneschi, L. Brambilla, E. Melotti, and A. F. Finzi. 1990. Immunohistological evaluation of basal cell carcinoma immunoinfiltrate during intralesional treatment with alpha 2-interferon. Arch. Derma tol. Res. 282:311-317

9. Tank, B., J. M. Habets, B. Naafs, O. Damsma, E. Stolz, and T. van Joost. 1989. Intralesional treatment of basal cell carcinoma with low-dose recombinant interferon gamma. J. Am. Acad. Dermatol. 21:734-735.

10. Mihara, M., H. Nakayama, K. Nakamura, T. Morimura, Y. Hagari, and S. Shimao. 1991. Histologic changes in basal superficial basal cell carcinoma and Bowen's disease by intralesional injection of recombinant interleukin-2: recombinant interleukin-2 may induce redifferentiation of malignant tumor cells in vivo. Arch. Dermatol. 126:1107.

11. Belldegrun, A., A. Kasid, M. Uppenkamp, S. L. Topalian, and S. A. Rosenberg. 1989. Human tumor infiltrating lymphocytes. Analysis of lymphokine mRNA expression and relevance to cancer immunotherapy. J. Immunol. 142:4520-4526.

12. Yamamura, M., K. Uyemura, R. J. Deans, K. Weinberg, T. H. Rea, B. R. Bloom, and R. L. Modlin. 1991. Defining protective responses to pathogens: cytokine profiles in leprosy lesions. Science (Wash. DC). 254:277-279.

13. Yamamura, M., X. -H. Wang, J. D. Ohmen, K. Uyemura, T. H. Rea, B. R. Bloom, and R. L. Modlin. 1993. Cytokine patterns of immunologically mediated tissue damage. J. Immunol. In press.

14. Salgame, P., J. S. Abrams, C. Clayberger, H. Goldstein, J. Convit, R. L. Modlin, and B. R. Bloom. 1991. Differing lymphokine profiles of functiona subsets of human CD4 and CD8 T cell clones. Science (Wash. DC). 254:279282.

15. Mosmann, T. R., H. Cherwinski, M. W. Bond, M. A. Giedlin, and R. L.
Coffman. 1986. Two types of murine helper T cell clones I. Definition according to profiles of lymphokine activities and secreted proteins. J. Immunol. 136:23482357.

16. Heinzel, F. P., M. D. Sadick, B. J. Holaday, R. L. Coffman, and R. M. Locksley. 1989. Reciprocal expression of interferon gamma or interleukin 4 during the resolution or progression of murine leishmaniasis. Evidence for expansion of distinct helper T cell subsets. J. Exp. Med. 169:59-72.

17. Pond, L., D. L. Wassom, and C. E. Hayes. 1989. Evidence for differential induction of helper $\mathrm{T}$ cell subsets during Trichinella spiralis infection. $J$. Im munol. 143:4232-4237.

18. Pearce, E. J., P. Caspar, J. -M. Grzych, F. A. Lewis, and A. Sher. 1991. Downregulation of Th1 cytokine production accompanies induction of Th2 responses by a parasitic helmith, Schistosoma mansoni. J. Exp. Med. 173:159-166.

19. Romagnani, S. 1991. Human TH1 and TH2 subsets: doubt no more. Immunol. Today. 12:256-257.

20. Kapsenberg, M. L., E. A. Wierenga, J. D. Bos, and H. M. Jansen. 1991 Functional subsets of allergen-reactive human CD4+ T cells. Immunol. Today. 12:392-395.

21. Bloom, B. R., P. Salgame, and B. Diamond. 1992. Revisiting and revising T suppressor cells. Immunol. Today. 13:131-136.

22. Wierenga, E. A., M. Snoek, C. de Groot, I. Chretien, J. D. Bos, H. M Jansen, and M. L. Kapsenberg. 1990. Evidence for compartmentalization of functional subsets of CD4+ $\mathrm{T}$ lymphocytes in atopic patients. J. Immunol. 144:4651-4656.

23. King, C. L., E. A. Ottesen, and T. B. Nutman. 1990. Cytokine regulation of antigen-driven immunoglobulin production in filarial parasite infections in humans. J. Clin. Invest. 85:1810-1815.

24. Grimwood, R. E., and M. D. Tharp. 1991. Growth of human basal cell carcinomas transplanted to $\mathrm{C} 57 / \mathrm{Balb} / \mathrm{C}$ bg/bg-nu/nu (Beige-Nude) Mice. $J$. Dermatol. Surg. Oncol. 17:661-666.

25. Moore, K. W., P. Vieira, D. F. Fiorentino, M. L. Trounstine, T. A. Khan, and T. R. Mosmann. 1990. Homology of cytokine synthesis inhibitory factor (IL-10) to the Epstein-Barr virus gene BCRFI. Science (Wash. DC). 248:12301234.

26. Ben-Sasson, S. Z., G. Le Gros, D. H. Conrad, F. D. Finkelman, and W. E. Paul. 1990. Cross-linking Fc receptors stimulate splenic non-B, not-T cells to secrete interleukin 4 and other lymphokines. Proc. Natl. Acad. Sci. USA. 87:1421-1425.

27. Enk, A. H., and S. I. Katz. 1992. Identification and induction of keratinocyte-derived IL-10. J. Immunol. 149:92-95.

28. Martinez, O. M., R. S. Gibbons, M. R. Garovoy, and F. R. Aronson. 1990 IL-4 inhibits IL-2 receptor expression and IL-2-dependent proliferation of human T cells. J. Immunol. 144:2211-2215.

29. Peleman, R., J. Wu, C. Fargeas, and G. Delespesse. 1989. Recombinant interleukin 4 suppresses the production of interferon gamma by human mononuclear cells. J. Exp. Med. 170:1751-1756.

30. Hart, P. H., G. F. Vitti, D. R. Burgess, G. A. Whitty, D. S. Piccoli, and J. A. Hamilton. 1989. Potential antiinflammatory effects of interleukin 4: suppression of human monocyte tumor necrosis factor alpha, interleukin 1, prostaglandin E2. Proc. Natl. Acad. Sci. USA. 86:3803-3807.

31. Vieira, P., R. de Waal-Malefyt, M. -N. Dang, K. E. Johnson, R. Kastelein D. F. Fiorentino, J. E. deVries, M. -G. Roncarolo, T. R. Mosmann, and K. W. Moore. 1991. Isolation and expression of human cytokine synthesis inhibitory factor cDNA clones: homology to Epstein-Barr virus open reading frame BCRFI Proc. Natl. Acad. Sci. USA. 88:1172-1176.

32. North, R. J., M. Awwad, and P. L. Dunn. 1989. The immune response to tumors. Transplant. Proc. 21:575-577.

33. Tepper, R. I., P. K. Pattengale, and P. Leder. 1989. Murine interleukin-4 displays potent antitumor activity in vivo. Cell. 57:503-507.

34. Ebina, N., D. Gallardo, H. Shau, and S. H. Golub. 1990. IL-1 and IL-4 as reciprocal regulators of IL-2 induced lymphocyte cytotoxicity. Br. J. Cancer 62:619-623.

35. Kupper, T., P. Flood, D. Coleman, and M. Horowitz. 1987. Growth of an interleukin 2 /interleukin 4-dependent $T$ cell line induced by granulocyte-macrophage colony-stimulating factor (GM-CSF). J. Immunol. 136:4288-4292.

36. Gajewski, T. F., M. Pinnas, T: Wong, and F. W. Fitch. 1991. Murine Th1 and $\mathrm{Th} 2$ clones proliferate optimally in response to distinct antigen-presenting cell populations. J. Immunol. 146:1750-1758.

37. Murray, J. S., J. Madri, J. Tite, S. R. Carding, and K. Bottomly. 1989. MHC control of CD4+ T cell subset activation. J. Exp. Med. 170:2135-2140.

38. Simon, J. C., P. D. Cruz, P. R. Bergstresser, and R. E. Tigelaar. 1990. Low dose ultraviolet B-irradiated Langerhans cells preferentially activate CD4+ cells of the T helper 2 subset. J. Immunol. 145:2087-2091. 